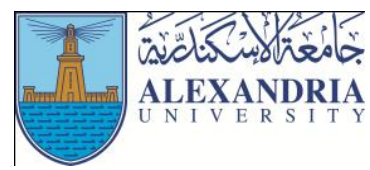

\title{
The Effect of a Cross-Training Program on the Body Composition, the Physical Working Capacity and the Record Level of 5000m Runners
}

\author{
Essam Ahmed Helmy Mohamed AbouGamil ${ }^{1}$ \\ ${ }^{1}$ Department of Athletic Training and Kinesiology, Faculty of Physical Education, Port Said University, Egypt
}

\begin{abstract}
:
This research aimed to identify the effect of the cross-training on each of the two variables of body composition (B.C.) [fat mass (F.M.) \& muscle mass (M.M.)], the physical working capacity (P.W.C.), and the record level of 5000m runners (R.L.5000m runners). The researcher used the experimental approach by the design of per-post measurements of two equal groups, one of them was the control group and the other was the experimental group, each group consisted of 6 of $5000 m$ runners. A cross-training program was applied on the experimental group, while a conventional-training program was applied on the control group, with taking into account the equality of the time and the intensity of the training units in between the two programs to the maximum extent possible, the two training programs lasted for 10 weeks without the two weeks of per \& post measurements, training program of the experimental group was included bicycling, training with cycle ergometer \& rowing machine, running in shallow water, aqua jogging, rope jumping, and versa climber, as cross-training activities.
\end{abstract}

The results indicated that cross-training was statistically significant more effective than the conventional-training for developing the level of (P.W.C.), and (R.L.5000m runners), but wasn't statistically significant more effective than the conventional-training for improving each of the two variables of (B.C.), [(F.M.) \& (M.M.)], but statistically insignificant.

Keywords: Cross-training - body composition - fat mass - muscle mass - physical working capacity - running - aerobic endurance

\section{Introduction}

$\mathrm{R}$ unning is one of the most demanding sport activities, especially as long as the specialist running distance of the runner, the training units of the training programs of this sport last for long periods of time, and the most of these units is performed on one frequent frequency, this causes a higher rate of injuries resulting from severe physical exhaustion (Hsan, 2016, 371-376), researchers had reported that $37-56 \%$ of regular runners in training are injured each year (Bryan, 2012, 1). This also causes rise to boredom, which leads to reduce motivation for training (Hsan, 2004, 383), and negatively affects the intensity of the runner performance in training, which leads in turn to limit the progression level of the runner and what he can achieve in his specialized competitions.

Cross-training is one of the modern training trends in sport , in which training programs are built from several types of different sport activities and physical performances with common components in order to raise the performance level of the athlete in his specialized sport (Bryan, 2012, 1; Guisado, 2005; Hsan, 2004; Leyland, 2008; Luis, et. al. 2013; MacNeill, 2012; Paine, et. al. 2010; Samill, 2002; Wilmore, et. al. 2008, 248), crosstraining develops physical fitness, provides the necessary recovery for the stressful muscle groups, improves the muscle balance, reduces the incidence of injuries, eliminates the training monotony, increases the motivation, and reduces the psychological boredom resulting from the participation in the rigorous training programs (Glassman, 2007; Walker, 2007; Werner, \& Sharon, 2011, 292) which makes the athlete performs the required training tasks in the appropriate intensities, this reflects positively on the performance level of the athlete and his results in his specialized competitions. The importance of cross-training is more evident in aerobic endurance sports which depend on cutting long distances in as little time as possible and their training programs are predominated by one frequent frequency (Hsan, 2004, 286) such as the sport of running for long distances. But there is a conflict between some references and the 
findings of some researches on the effectiveness of crosstraining in developing the performance level of the athlete, while some suggested that cross-training is very effective in developing the performance level (Eaves, et. al. 2005; Elhadidi, 2011; Elsais, 2012; Joubert, et. al. 2001; Krause, 2009; Paine, et, al. 2010), others pointed out that crosstraining is less effective than conventional-training in developing the performance level (Bryan, 2012, 1). This motivated the researcher to attempt to verify, through this research, the effect of using a cross-training program on the record level of $5000 \mathrm{~m}$ runners (R.L.5000m runners) as athletes of one of those sports.

The cross-training program for long distance runners can include a great variety of unconventional training activities which depends on the aerobic endurance and muscular endurance of the most of body muscle groups, especially leg muscles, such as, bicycling, training with cycle ergometer \& rowing machine, running in shallow water, aqua jogging, rope jumping, and versa climber (Bryan, 2012; Hsan, 2012; Hsan, 2004, 277-290). That variety may maximize the positive effects of training on the long-distances runners, in particular, because their sport is one of the most important aerobic endurance sports which relies on performing one frequent frequency for long periods of time through the training processes, which in turn leads to boredom and severe physical exhaustion of working muscles in running, but that variety may alleviate this boredom and exhaustion, and achieve those mentioned advantages of cross-training for runners, this may rise the effectiveness of the training program to improve (R.L.5000m runners).

Improving the body composition (B.C.) by reducing the percentage of its fat mass (F.M.) to its muscle mass (M.M) is a primary objective in the training of the long-distance runners, because it has a positive effect on the level of the runner's record (Bassett, \& Howley, 2000; Damian, 2015; Donnelly, 2009; Jakicic, et. al. 2006; Kraemer, et. al. 2012; Maciejczyk, et, al. 2014; Ramana, et. al. 2004; Ucan, 2014). The sport of running for long-distance, as one of the aerobic endurance activities, improves (B.C.) due to their great contribution of burning fat to release the required energy for the physical performance in that sport activity (Abdelfatah, \& Nasereldeen, 1993, 73; Arazi, et. al. 2011; Doucet, et. al. 2003; Hunter, et. al. 2008; Hottenrottl, et. al. 2012; Kostić, et, al. 2006; Layman, et. al. 2005), but, some researches concluded that aerobic training not only reduces (F.M.) but also reduces (M.M.) (Lehri, \& Mokha, 2006), this may negatively affect the level of the runner's record, because of that, it is important to recognize the effect of cross-training on improving (B.C.) of the $5000 \mathrm{~m}$ runners.
The physical working capacity (P.W.C.) is the body ability to provide the required aerobic and anaerobic energy to perform the maximum muscular work as long time as possible (Abdelfatah, \& Nasereldeen, 1993a, 27; Abdelfatah, \& Nasereldeen,1985b, 84), which is one of the decisive factors of (R.L.5000m runners), so, it is also important to recognize the effect of cross-training on (P.W.C.) of these runners.

\section{Research Objective}

This research aimed at identify the effect of a crosstraining program on each of (B.C.), (P.W.C.), and (R.L.5000m runners).

\section{Research procedures}

The researcher used the experimental approach as it suited the research nature.

\section{Experimental Design:}

The researcher used per-post measurements of two equal groups, one was the control group and the other was the experimental group.

\section{Research sample:}

- The main sample consisted of (12) healthy runners at the age of 20-22 years, they were selected purposely from Port Fouad Club runners, which were registered in the Egyptian Athletics Federation. The runners of this sample were selected from this club because of the existence of this club in the coastal environment which is necessary to perform some of the included activities in the crosstraining program of the research such as running on the beach in shallow water, versa climber and aqua jogging.

- The pilot study sample consisted of (8) healthy runners, they were selected purposely from Elrabat Club runners. The runners of this sample were selected from this club because of the existence of this club in the same environment of the main sample.

\section{Data collection tools:}

a - [Tanita - Model TBF-300A] device, (Appendix 1) to measure the two variables of (B.C.), [(F.M.) \& (M.M.)], this device can measure (F.M.) and the lean body mass as an indicator of (M.M.), and was selected because of its ease and speed in measuring the intended variables, this selection was supported by experts through a expert consultation form (Appendix3)

b - Harvard Step Test, (Appendix 2) to measure (P.W.C.), this test was selected because it is one of the oldest tests which measure this variable and its validity has been 
confirmed in many researches across generations, this selection was also supported by experts through the same expert consultation form (Appendix3)

c - An expert consultation form about some of the research procedures, (Appendix3).

\section{The pilot study:}

The pilot study was conducted on its sample in the period from 24.06.2017 to 30.06.2017 for the purpose of making sure that the [Tanita - Model TBF-300A] device was suitable and logically valid to measure the two variables of (B.C.), [(F.M.) \& (M.M.)], and to identify the logical validity and the reliability of the Harvard Step Test (Appendix 4) .

\section{The pre-measurements :}

The pre-measurements were conducted in the period from 01.07.2017 to 07.07.2017, its data are shown in table (1).

\section{The training program:}

The training program was applied in Port Fouad Club and Physical Education Faculty at Port Said in the period from 08.07.2017 to 15.09.2017, it was designed on the following bases

- The program should be in accordance with the rules and foundations of building training programs for long distance runners.

- The only difference between the cross-training program of the experimental group and the conventional-training program of the control group was just the use of unconventional cross training activities, which were bicycling, training with cycle ergometer \& rowing machine, running in shallow water, aqua jogging, rope jumping and versa climber, in the cross-training program in addition to the conventional running and resistance activities, while the conventional-training program included only the conventional running and resistance activities, this difference was with taking into account the equal time of the training units between the two programs.

- Exercises with the use of cycle ergometer and rowing machine were considered from strength exercises, while bicycling, running in shallow water, aqua jogging, rope jumping, and versa climber were considered parallel to running exercises.

- The training program consists of ten microcycles, ten training weeks, should be completed before the 2017 Republic Championship for adults with suitable time, for the individual preparation of the runners according to each individual case.
- Each microcycle, training week, included three training units, each of them was in one-day, thus the training program included thirty training units, each unit lasted for $90 \mathrm{~min}-180 \mathrm{~min}$.

- All the program microcycles contained strength exercises, except the last microcycle before the postmeasurements in order to exclude the negative effects of fatigue from strength exercises on the measurement results as much as possible.

- The weekly training units for control group were on Saturday, Monday and Wednesday, while these units for experimental group were on Sunday, Tuesday and Thursday.

- Heart rate was used to adjust the training intensity of the parallel parts in between the training units of the two groups, which were included differences because of the entry of the cross-training activities on the training program of the experimental group.

- Consideration was given to each of rippling the training load levels in the microcycles designing, the compatibility with the properties of the sample age group, the available training tools \& devices, and the individual differences between the runners, in additional to the factors of safety.

Some experts were consulted about the most important bases of building the training program which abovementioned through the expert consultation form (Appendix 3), some adjustments were made in the light of their opinions.

In the appendixes, (Appendix5) shows the timetable division of the research training program, the levels of intensities \& volumes used in each training unit, and the curves of the general weekly intensity \& volumes. (Appendix 6) shows three units form training program units, each of them in one of the three periods of the training program.

\section{The post-measurements:}

The post-measurements were conducted in the period from 16.09.2017 to 22.09.2017, Its data are shown in table (2).

\section{Statistics used:}

The researcher used the Non-Parametric Statistics for the treatment of the research data, because the runners number of the sample of any of main study or pilot study was $<30$ (Radwan, 2003, 79) . This smallness of the samples was due to the scarcity of runners at the clubs level, especially in the age group of the research samples. The researcher 
used Spearman's Rank Correlation Coefficient and the Mann-Whitney Test for that treatment.

\section{Results and Discussion}

\section{Results:}

The following table shows the per-measurements data of the two research groups in each of the main and the experimental variables and the parity between them.

Table (1)

The per-measurements data of the control \& experimental groups and the statistical significance of the differences in between them $(\mathrm{N} 1=\mathrm{N} 2=6)$

\begin{tabular}{|c|c|c|c|c|c|c|c|c|c|}
\hline \multirow{2}{*}{\multicolumn{4}{|c|}{ Variables }} & \multicolumn{2}{|c|}{ Average of per-measurement of } & \multirow{3}{*}{$\begin{array}{c}\text { The } \\
\text { difference } \\
\text { between the } \\
\text { two groups }\end{array}$} & \multicolumn{2}{|c|}{ Ranks sum of } & \multirow{3}{*}{$\begin{array}{c}\begin{array}{c}\text { Degree of } \\
\text { Mann } \\
\text { Whitney } \\
\text { test } \\
(T)\end{array} \\
14 \\
\end{array}$} \\
\hline & & & & \multirow{2}{*}{\begin{tabular}{|c|}
$\begin{array}{c}\text { Control } \\
\text { group }\end{array}$ \\
21.17
\end{tabular}} & \multirow{2}{*}{$\begin{array}{c}\begin{array}{c}\text { Experimental } \\
\text { group }\end{array} \\
20.83\end{array}$} & & \multirow{2}{*}{$\begin{array}{c}\begin{array}{c}\text { Control } \\
\text { group } \\
\text { (S1) }\end{array} \\
43 \\
\end{array}$} & \multirow{2}{*}{$\begin{array}{c}\begin{array}{c}\text { Experimental } \\
\text { group } \\
\text { (S2) }\end{array} \\
35 \\
\end{array}$} & \\
\hline 1 & \multirow{3}{*}{$\sum \frac{\mathscr{0}}{\frac{0}{0}}$} & \multicolumn{2}{|c|}{ Age $[\mathrm{yr}]$} & & & & & & \\
\hline 2 & & \multicolumn{2}{|c|}{ Height $[\mathrm{cm}]$} & 180.17 & 180.33 & 0.16 & 41 & 37 & 16 \\
\hline 4 & & \multicolumn{2}{|c|}{ Training age $[\mathrm{yr}]$} & 7.00 & 7.17 & 0.17 & 37 & 41 & 16 \\
\hline 5 & \multirow{4}{*}{ 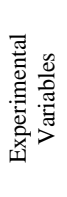 } & \multirow{2}{*}{$\begin{array}{c}\text { (B.C.) } \\
\text { Variables }\end{array}$} & (F.M.) $[\mathrm{kg}]$ & 11.17 & 11.08 & -0.09 & 38.5 & 39.5 & 17.5 \\
\hline 6 & & & $\begin{array}{c}\text { (M.M.) } \\
{[\mathrm{kg}]}\end{array}$ & 65.83 & 65.42 & -0.41 & 38.5 & 39.5 & 17.5 \\
\hline 7 & & \multicolumn{2}{|c|}{ (P.W.C.) [degree] } & 61.17 & 61.50 & 0.33 & 39.5 & 38.5 & 17.5 \\
\hline 8 & & \multicolumn{2}{|c|}{ (R.L.5000m runners) [min] } & $17 ; 43.40$ & $17 ; 43.62$ & $00 ; 00.22$ & 39 & 39 & 18 \\
\hline
\end{tabular}

The upper and lower limits of the indexed (T) value when the two groups before the applying of the training $\mathrm{N} 1=\mathrm{N} 2=6$ at the level of 0.05 are $6 \& 30$ respectively.

In table 1 , it is clear that all calculated $(\mathrm{T})$ values of the Mann-Whitney Test were lied between the upper and lower limits of the indexed (T) value, accordingly, there were no statistical differences between the two research groups (Radwan, 2003, 261), this indicated the parity of program.

The following table shows the results of the postmeasurements of the two research groups, the differences in between them, and their statistical significances, regarding each of the experimental variables.

Table (2)

The post-measurements data of the control $\&$ the experimental groups and the statistical significance of the differences in between them $(\mathrm{N} 1=\mathrm{N} 2=6)$

\begin{tabular}{|c|c|c|c|c|c|c|c|c|}
\hline & & & Average of & -measurement & The & & um of & $\begin{array}{c}\text { Degree of } \\
\text { Mann }\end{array}$ \\
\hline & Experimental V & & Control & Experimental & between the & Control & Experimental & Whitney \\
\hline 1 & & (F.M.) $[\mathrm{kg}]$ & 8.42 & 8.25 & -0.17 & 40 & 38 & 17 \\
\hline 2 & (B.C.) Variables & $\begin{array}{c}\text { (M.M.) } \\
{[\mathrm{kg}]}\end{array}$ & 67.25 & 68.42 & 1.17 & 38.5 & 39.5 & 17.5 \\
\hline 3 & (P.W.C.) [ & & 66.83 & 72.67 & 5.84 & 25 & 53 & $4 *$ \\
\hline 4 & $\begin{array}{r}\text { (R.L.5000m } \\
\text { [mir }\end{array}$ & & $17 ; 12.99$ & $16 ; 43.53$ & $-00 ; 29.46$ & 56 & 22 & $1^{*}$ \\
\hline
\end{tabular}

The upper and lower limits of the indexed (T) value when $\mathrm{N} 1=\mathrm{N} 2=6$ at the level of 0.05 are $6 \& 30$ respectively.

In table 2 , it is clear that the calculated $(\mathrm{T})$ values of the Mann-Whitney Test came less than the indexed $(\mathrm{T})$ value with regard of (P.W.C.) and (R.L.5000m runners), this proved the statistical significance of the differences in between the two groups of these variables (Radwan, 2003, 261). But it is clear also in the table that the calculated (T) values lied between the upper and lower limits of the indexed (T) value with regard of the (B.C.) variables, [(F.M.) \& (M.M.)], which indicated that the differences between the two groups of these variables were statistically insignificant (Radwan, 2003, 261). It is also clear from the same table that all differences between the averages were in favor of the experimental group for all the experimental variables. 
The following figure shows the percentages of the progress from the per-to-post measurements of each of the

two research groups in all the experimental variables.

Figure (1)

The progress percentages of the two research groups

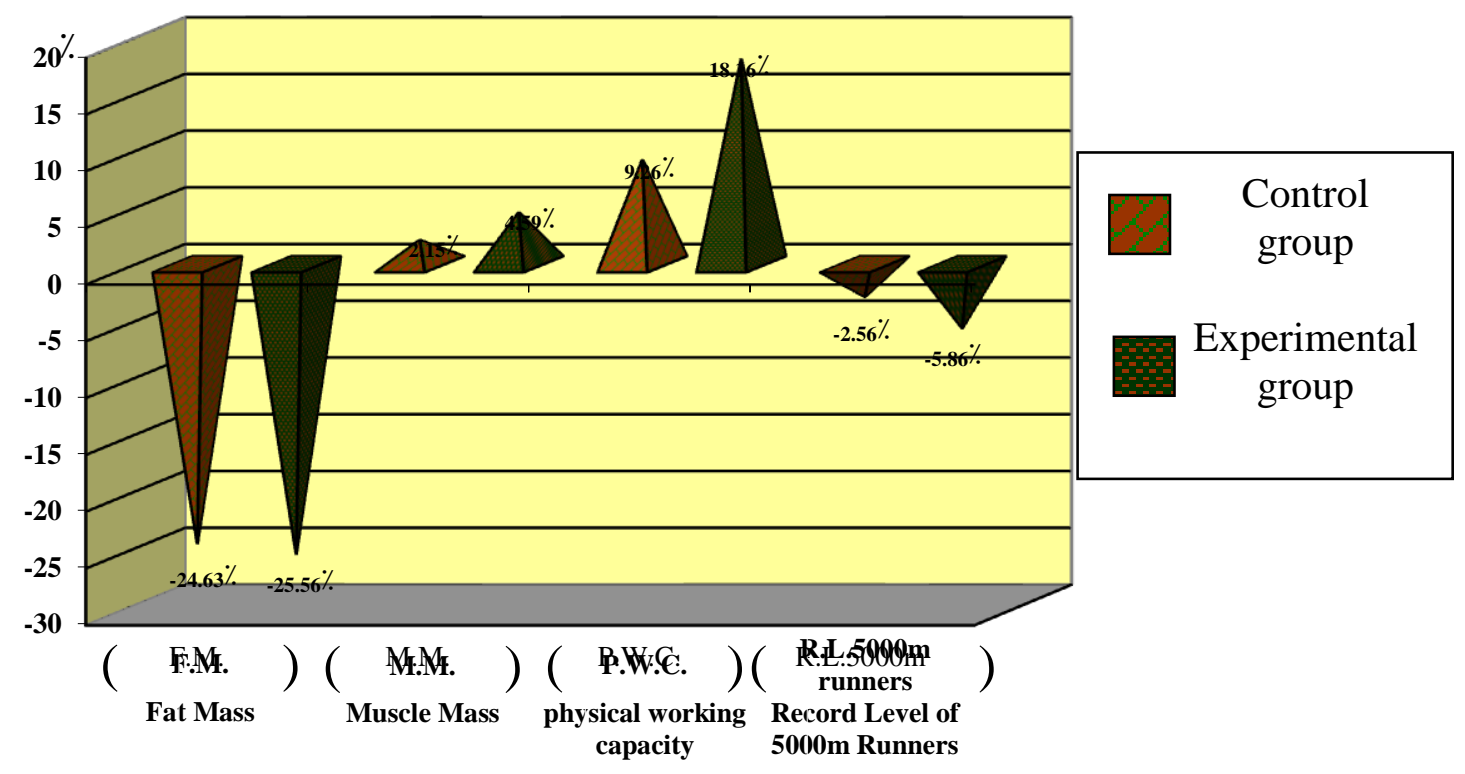

It is clear from the previous figure that the progress percentages of the experimental group exceeded the progress percentages of the control group in all variables, and that the progress of (F.M.) and (R.L.5000m runners) variables were in the opposite direction of the other variables, which is consistent with the nature of those variables.

\section{Discussion:}

Based on table 2, by comparing the measurement averages of pre \& post measurements of each of the control group $\&$ the experimental group in all the experimental variables, and by comparing the measurement averages of the post measurements of all these variables in between the two groups, it is clear that both the conventionaltraining program of the control group and the crosstraining program of the experimental group had a positive effect on the two groups in all the experimental variables, but, this positive effect was greater for the experimental group in all these variables, and this was supported by figure 1 .

It is logical that each of the two training programs had a positive effect on all the experimental variables under research, because the objective of both of them was the improving of (R.L.5000m runners), thus the training loads of the two programs were predominated by aerobic loads, these loads not only improve (R.L.5000m runners), but also improve the release of aerobic energy which raises the level (P.W.C.) (Abdelfatah, \& Nasereldeen, 1993a, 27; Abdelfatah, \& Nasereldeen,1985b, 84), and improve the (B.C.) variables, [(F.M.) \& (M.M.)], by increase the rate of fat burning and muscle building. The researcher attributes the greater positive effect for the experimental group in all those variables to the cross training program of this group, the diversification of cross-training activities helped to reduce the boredom experienced by the runners from practicing on one frequent frequency for the most of the training time, the runners in turn performed the training loads with the required intensities, this led to that greater positive effect, as for all physical abilities in general (Elhadidi, 2011; Elsais, 2012; Hadfield, 2010; Leyland, 2008; Partridge, et. al. 2014; Smith, et. al. 2013; Urbian, et. al. 2013).

Although cross-training had a more positive effect on all the experimental variables, as shown in Figure 1, the differences between the two research groups didn't reach the level of statistical significance for the (B.C.) variables, [(F.M.) \& (M.M.)] as shown in table 2, therefore it is not possible to consider that the cross-training program is better than the conventional-training program to improve the level of these variables, the researcher attributes that those differences were not wide enough to reach the level 
of significance might be because of the (B.C.) variables of the regular runners, as in the research sample, were already good and the possibility to improve them is very limited.

The difference between the two groups was statistically significant for the (P.W.C.) variable, as shown in table 2, the researcher attributes this to that the cross-training program contained unconventional activities which had higher effects to release aerobic energy and improve the level of anaerobic threshold (Eaves, et. al. 2005; Elamir, 2015; Elsais, 2012; Joubert, et. al. 2011; Krause, 2009; Paine, et. al. 2010) while minimizing the fatigue of the working muscles and joints during the running, these activities were bicycling, aqua jogging, cycle ergometer, and versa climber (Brahler, \& Blank, 1995; Kisan, et. al., 2012; Quigley, \& Richards, 1996; Puleo, \& Milroy, 2012), these activities were not included in the conventionaltraining program, resulting in the statistically significant difference between the two research groups in favor of the experimental group in regard of the (P.W.C.) variable.

That higher effects to release aerobic energy and the greater improving of the anaerobic threshold level resulted in improving more effectively the ability of aerobic endurance for the runners the experimental group, because of the aerobic endurance is one of the most important factors of (R.L.5000m runners), the researcher sees that this is one of the most important reasons for the statistically significant difference between the two research groups in favor of the experimental group for the (R.L.5000m runners) variable as shown in table 2, (Eaves, et. al. 2005; Joubert, et. al. 2011; Krause, 2009; Paine, et. al. 2010), this also due to that the activities of bicycling, cycle ergometer, aqua jogging, running in shallow water, and rope jumping in the cross-training program worked more efficiently to improve the muscular endurance and power of the leg muscles (Kisan, et. al., 2012; Meyer, 2008; Quigley, \& Richards, 1996; Puleo, \& Milroy, 2012), the cross training program also contained the training with rowing machine which strengthened the muscles of the core, the back and the arms, this helped the runners to keep their posture upright, which in turn made them breathe freely to get more oxygen despite growing fatigue through the race performance (Murphy, 2017), this was in additional to that the rope jumping in the cross-training program was more effective to improve the speed, the agility, the balance and the co-ordination for the experimental group runners (Meyer, 2008), all of these were reasons for that statically significant difference in regard of (R.L.5000m runners) variable.

\section{Conclusions}

Within the framework of the research objectives, fields and limits, the researcher can conclude the following

1 - The cross-training is more effective than the conventional-training to improve (P.W.C.) for $5000 \mathrm{~m}$ runners.

2 - The cross-training is likely to be more effective than the conventional-training to improve (R.L.5000m runners).

3 - The cross-training is not more effective than the conventional-training to improve (B.C.) for $5000 \mathrm{~m}$ runners.

\section{Recommendations}

1 - It is preferred to use the cross-training programs for $5000 \mathrm{~m}$ runners in order to increase the training effectiveness to improve their record of their specialized race.

2 - It has to be kept in mind that the cross-training programs are more effective than the conventional-training programs to improve (P.W.C) for $5000 \mathrm{~m}$ runners.

3 - More researches are needed to further confirmation to the results of this research and to investigate the effect of the cross-training on improving all of the physical abilities and athletic achievements in all sporting activities.

4 - More researches are needed to investigate the effect of the cross-training on improving (B.C.) variables for the non-athletes and for the athletes who are not regular in training.

\section{References}

1 - Abdelfatah, A. \& Nasereldeen, A. (1993). Physiology of physical fitness. Cairo: Dar Elfekr Alarabi.

2 - Abdelfatah, A. \& Nasereldeen, A. (1985). Biology of sport. Cairo: Dar Elfekr Alarabi.

3 - Arazi, H., Faraji, H., Moghadam, M. G., \& Samadi, A. (2011). Effects of concurrent exercise protocols on strength, aerobic power, flexibility and body composition, Kinesiology Journal, 43(2),155-162.

4 - Bassett, D. R. \& Howley, E. T. (2000). Limiting factors for maximum oxygen uptake and determinants of endurance performance, Medicine and Science in Sports and Exercise, 32,70-84.

5 - Brahler, C. J, \& Blank, S. E. (1995). VersaClimbing elicits higher VO2max than does treadmill running or 
rowing ergometry, Medicine \& Science in Sports \& Exercise, 27(2):249-54 .

6 - Bryan, W. (2012). The Trainer's guide to cross training. Colorado: Better Runner.

7 - Damian, S. (2015). Effects of endurance and endurance strength training on body composition and physical capacity in women with abdominal obesity, The European Journal of Obesity, 8,175-187.

8 - Donnelly, J. E. (2009). Appropriate physical activity intervention strategies for weight loss and prevention of weight regain for adults, Medicine and Science in Sports and Exercise, 41,459-471.

9 - Doucet, E., Tremblay, A., Simoneau, J. A., Joanisse, D.R. (2003). Skeletal muscle enzymes as predictors of 24$\mathrm{h}$ energy metabolism in reduced-obesed persons, The American Journal of Clinical Nutrition, 78(3),430-435.

10- Eaves, J. E., Hughes, D. M., \& Lamb, L. K. (2005). The consequences of the introduction of professional playing status on game action variables in international northern hemisphere rugby union football, International Journal of Performance Analysis in Sport, 5 (2),58-86.

11- Elamir, H. A. (2015). The effect of using crosstraining in developing the physical efficiency of legs movements for tall basketball players, International Journal of Advanced Sports Researches, 2(3),831-852.

12- Elhadidi, R. O. (2011). The effectiveness of crosstraining on some physical abilities and psychological rigidity and the performance level of long jump skill, Journal of Physical Education Researches, 45(85),122135 .

13- Elsais, M. A. (2012). The effectiveness of crosstraining on some physical variables and blood components of $400 \mathrm{~m}$ runners, Journal of Science and Sports Arts, 41,87-102.

14- Hadfield, J. (2010, August 18). Elliptigo: cross training for runners, Runner's World on line Journal, https://www.runnersworld.com/ask-coach-jenny/elliptigocross-training-for-runners/ .

15- Hunter, G. R., Byrne, N. M., Sirikul, B., Fernández, J. R., Zuckerman, P. A., Darnell, B. E., \& Gower, B. A. (2008). Resistance training conserves fat-free mass and resting energy expenditure following weight loss, Obesity Journal, 16(5),1045-1051.

16- Glassman, G. (2007). Understanding crossfit, CrossFit Journal, 56,1-3.
17- Guisado, R. (2005). Cross training for endurance athletes: building, stability, balance, strength. Sydney: Peak Sports Press.

18- Hottenrott1, K., Ludyga, S., \& Schulze1, S. (2012). Effects of high intensity training and continuous endurance training on aerobic capacity and body composition in recreationally active runners, Journal of Sports Science and Medicine, 11,483-488.

19- Hsan, H. F. (2013). The effect of hardening exercises for legs muscles only by the using of fixed and moving bike to develop some physical abilities and achieving $100 \mathrm{~m}$ running in track and field events, Journal of Physical Education Sciences, 3(6),198-227.

20- Hsan, Z. M. M. (2016). The ergonomics and sports engineering in the field of sports. Cairo: Dar of the Modern Book.

21- Hsan, Z. M. M. (2004). Cross-training is a modern trend in sports training. Alexandria: The Egyptian Library.

22- Jakicic, J. M., \& Otto, A. D. (2006). Treatment and prevention of obesity: what is the role of exercise ?, Journal of Nutrition Reviews, 2,57-61.

23- Joubert, D. P., Oden, G. L., \& Estes, B. C. (2011). The effects of elliptical cross training on $\mathrm{VO} 2 \mathrm{max}$ in recently trained runners, International Journal of Exercise Science, $4(1), 4-12$.

24- Kisan, R. M., Kisan, S. M., Anitha, O. R. \& Chandrakala, S. P. (2012). Treadmill and bicycle ergometer exercise: cardiovascular response comparison, Global Journal of Medical Research, 12(5),22-26.

25- Kostić, R., Đurašković, R., Miletić, D., \& Mikalački, M. (2006). Changes in the cardiovascular fitness and body composition of women under the influence of the aerobic dance, Physical Education and Sport, 4(1),59-71.

26- Kraemer, W. J., Fleck, S. J., \& Deschenes, M. R. (2012). Exercise physiology integrating theory and application. Baltimore: Lippincott Williams \& Wilkins.

27- Krause, P. (2009). The benefits of cross-training. Bethesda, Maryland: American Medical Athletic Association.

28- Layman, D. K., Evans, E., Baum, J.I., Seyler, J., Erickson, D.J., \& Boileau, R.A. (2005). Dietary protein and exercise have additive effects on body composition during weight loss in adult women, The Journal of Nutrition, 135(8),1903-1910. 
29- Lehri, A., \& Mokha, R. (2006). Effectiveness of aerobic and strength training in causing weight loss and favourable body composition in females, Journal of Exercise Science and Physiotherapy, 2,96-99.

30- Leyland T. : (2008, July 01). Human power output and crossfit metcon outworks, CrossFit Journal, http://journal.crossfit.com/2008/07/human-power-outputand-crossfi.tpl/ .

31- Luís, V. , Eduardo, A., Helder, F. M., \& Victor R. M. (2013). Cross-training in rugby: a review of research and practical suggestions, International Journal of Performance Analysis in Sport, 13,225-237.

32- Maciejczyk, M., Więcek, M., Szymura, J., Szyguła, Z., Wiecha, S., \& Cempla, J. (2014). The influence of increased body fat or lean body mass on aerobic performance, Public Library of Science Journal, 9(4), 1-6.

33- MacNeill, L. (2012). The beginning runners handbook. Canada: Greystone Books.

34- Meyer, T. (2008). Benefits of Jumping Rope for Athletes, International Youth Conditioning Association, http://iyca.org/benefits-jumping-rope-for-athletes/ .

35- Murphy, T. J. (2017). Why Runners Should be Rowers?, Active, https://www.active.com/running/articles/why-runnersshould-be-rowers/ .

36- Paine, M. J., Uptgraft, M. J., \& Wyile, M. R. (2010). Crossfit study. Washington: Headquarters Services.

37- Partridge, G. A., Knapp, B. A., \& Massengale, B. D. (2014). An investigation of motivational variables in crossfit facilities, Journal of Strength Condition Research, 28(6),1714-1721.

38- Puleo, J., \& Milroy, P. (2012), Running anatomy, Champaign : Human Kinetics.
39- Quigley, E. J., Richards, J. G. (1996). The effects of cycling on running mechanics, Human Kinetics Journals , 12(4),470-479.

40- Radwan, M. N. (2003). Inferential statistics in the science of physical education and sports. Cairo: Dar Elfekr Alarabi.

41- Ramana, V. Y., Mvl, S. K., Rao, S. S., \& Balakrishna, N. (2004). Effect of changes in body composition profile on VO2max and maximal work performance in athletes, Journal of Exercise Physiology Online, 7(1),34-39.

42- Samill, L. S. E. (2002). Kids \& sports: every thing you and your child need to know about sports. New York: New Market Press.

43- Smith, M. M., Sommer, A. J., Starkoff, B. E., \& Devor, S. T. (2013). Crossfit-based high-intensity power trainings improves maximal aerobic fitness and body composition, Journal of Strength and Condition Research, 27(11),3159-3172.

44- Ucan, Y. (2014). Effects of circuit resistance training on body composition and bone status in young males, The Sport Journal, 19,52-65.

45- Urbian, S., Hayward, S., Jordan Outlaw, J., et. al. (2013). Performance and body composition effects of a pre-workout supplement and post-workout protein intake in trained crossfit individuals, Journal of International Society of Sports nutrition, 10(1),28.

46- Walker B. (2007). The anatomy of sports injuries. California: North Atlantic books.

47- Werner, W. K., \& Sharon, A. H. (2011). Lifetime physical fitness and wellness. Wadsworth, Ohio: Library of Congress Control.

48- Wilmore, J. H., Costill, D. L., \& Kenney, W. L. (2008). Physiology of sport and exercise. Champaign : Human Kinetics. 